\title{
Impression Curve as a New Tool in the Study of Visual Diversity of Computer Game Levels for Individual Phases of the Design Process
}

\author{
Jarosław Andrzejczak ${ }^{(凶)}(\mathbb{D}$, Marta Osowicz, and Rafał Szrajber (D) \\ Institute of Information Technology, Lodz University of Technology, \\ 215 Wólczańska Street, 90-924 Lodz, Poland \\ \{jaroslaw.andrzejczak, rafal.szrajber\}@p.lodz.pl \\ http://it.p.lodz.pl
}

\begin{abstract}
Impression curve is a widely used method in urban and landscape design to assess visual diversity of the space. In these studies, the method is applied for game level design. The goal of conducted research was the analysis of space perception in successive design phases related to the process of game environment formation. Next steps of the design process define the space burdened with more and more information. It aims to evaluate if initial assumptions, made by a designer at the beginning of the designing process, are maintained with the increase in the number of details and the content of locations. These studies are also a background for research in automation of visual diversity assessment. This, in turn, is related to making a player focused and interested during a gameplay, by the means of space defining an action scene. By applying a method from domain of urban planning and architecture in humancomputer interaction (HCI) studies related to virtual space, we show that both - defining the surroundings and its impact on recipient - are subject to the same rules in either case.
\end{abstract}

Keywords: Virtual environment $\cdot$ Level design · Game design · Virtual architecture $\cdot$ Impression curve $\cdot$ Experience design

\section{Introduction}

Game design became a pretty complex process, where experts from many domains are engaged in order to produce a user-oriented product. Games, being under continuous development, represent a very broad area of research. In classic media as movies, space is thought to be a background of events defining only the location and the time of action. In interactive environments, in turn, it is an interface dedicated to navigational and narrative purposes, which highly influences an observer because of its spatial composition. This kind of interaction determines if a system is perceived as an attractive one, or not. Experience of 
space, triggered by movement, requires spaces to be formed in such a way the impression of monotony and repeatability are diminished so that a system seems attractive to an observer.

Creation of diversified attractive, and engaging virtual environments led to strategies applied in other areas of studies, like architecture or urban design. Furthermore, digital characteristic of both description and exploration manners made these strategies enable to study and verify the theses stated in this paper for virtual environments.

The contributions to virtual worlds (Virtual Reality as well as video games levels) design and evaluation presented in this article are:

- The impression curve idea adaptation for virtual world creation (especially for video games level design process).

- Usability tests with 112 participants confirming the impact of usage of the impression curve in virtual worlds creation and evaluation.

- Identification of parameters affecting impression in virtual world.

We start with a impression curve definition and history. Next the impression curve adaptation for virtual world creation process idea detailed description in given. This is followed by a evaluation methodology and its stages construction as well as the some details of research environment design. Next, tests results and their discussion are presented. Finally, ideas for further development and final conclusions will be given.

\section{Impression Curve}

The strategy of impression curve was firstly elaborated on by Wejcherts in [8]. The method relies on relation among space, time, and velocity of impression forming. The author defined space as an interior or an interior layout being a component part of the structure of space. He emphasized that time and space, in successive interior layouts (e.g. street sequence), are inseparable. An observer who moves (motion enables three-dimensional perception) perceives spatial images, which are bonded to the shape of space where they are and which change over time. For impression curve no measure can be established, since it is a way how particular elements of space influence an observer.

Impression curve is depicted as a chart, where the horizontal axis is a time scale and the vertical one describes how a particular element of a scene influences an observer on the scale from 1 up to 10 . The maximal value of 10 is a conventional value being the result of the commonly used decimal system. Each value (from 1 to 10) was described by the Wejchert: value 1 describes monotonous system devoid of architectural merits. On the other hand, value 10 describes/presents a system of meaningful strong points, dominating as an element of city's structure. The studies showed that there is a clear group which react in the similar manner despite the subjective assessment of observers. Thanks to this, preparing an average chart on the basis of individual charts is 
possible. Based on the average chart, impression curve-based appraisal of the spatial system may be done and some basic conclusions about space perception may be drawn.

Wejchert suggests that street sequence should provide impression changes every 2 or $3 \mathrm{~min}$ to avoid the feeling of monotony. If so, it is clear that the level of diversity is dependent on the velocity of an observer and how much attention may he or she pay to the particular fragment of a route. Having analysed charts of impression curve for different streets, one may notice the decrease of value for long-lasting motion along repetitive fragments, even though they seemed interesting at the beginning. As a corollary, space changes are said to be as essential as visual quality of a scene.

Impression curve may be implemented both for new spaces design and for assessment of already existing areas. Thanks to it, valuable elements and elements requiring improvements might be easily identified [12]. Impression curve was widely used as a method for studying space diversity: identification of the most precious places at the Piotrkowska street, evaluation of landscape of countryside Panieńszczyzna in vicinity of Lublin [10] or organizing agrarian and landscape structures in Pojałowice countryside [18] are just a few examples to the point [1].

When analyzing the state of knowledge, it is worth referring to the search for various methods of exploring the reception of space in games and the player's experience. Research shown in $[9,11,16,19]$ affected the choice of our method and its application domain. Additionally [17] authors employs surveys to appraise emotional state of an entity. The key element is that those questions are introduced to the world of game so a survey may be carried out while playing. The goal of our search was first to create a system embedded in a virtual environment.

Other domains, like urban planning, interior or landscape design may also be helpful to figure comprehend how to build a functional and visually attractive game level. Dan Cox proves in his presentations that virtual spaces design and interior design have a lot in common. He also presents well known techniques of interior design, which are supportive in game level design $[2,3,5]$.

To sum up, impression curve may be thought of as a method, based on subjective grade, of valorisation of a landscape in either local or regional scale. A chart of impression curve depicts an average observers' judgement and a chart of deviation from the average reaction tends to form Gaussian distribution [7]. Although this method was introduced for architecture domain and it is widely applied therein, it may be considered in game level design as well. The first application of impression curve in design and analysis of virtual environments was proposed by Rafał Szrajber during [13] and [14]. Those speeches initiated the studies presented in this paper.

\section{Method}

The idea of the test method is to use an impression curve for the analysis of the visual diversity and attractiveness of game level. It assesses subjective attraction of a given space. An entity, being a subject of tests, moves along prepared route 
(in virtual space- controlling an avatar) and in predefined, equally spaced location, he or she evaluates how appealing the given fragment of environment is. The entity assigns grades from 1 to 10, where 1 means a boring scene, and 10- an exciting scene of high aesthetic merits. Impression curve seems to enable virtual spaces assessment even though it comes from architectural domain. Thanks to it, interesting elements of surroundings may be identified. An average chart of impression curve may be used also to localize and enhance poorly graded level fragments.

Sinusoidal shape is said to be the proper distribution of the computer game level impression curve. In uniformed long-lasting environment, the values of impression curves fall because a brain receives still the same set of stimuli in similar intensity [8]. In order to keep the constant or increasing trend, impressions should grow continuously. In case of game development industry it often wreaks much more resources to produce better set of models and more interesting environment. This may be difficult to achieve. If so, impression level may periodically grow and fall to reach successive increases without any extra expenses with respect to the previous ones. In addition, impression level should be always kept above some predefined threshold. Otherwise, it means that some parts of the game level observed should be definitively improved.

The proposed method is constrained to assessing quality of a single route. Without further extensions, it may appraise only linear levels, where a player cannot select an alternative direction. For more complex levels it should be assured that all players follow the predefined testing routes.

The method of impression curve was introduced to test different versions of computer game levels during successive phases of virtual space design. It aimed to answer if impression curve changes in successive design stages and by which factors it is affected. The goal was also to indicate from which stage of design process it is possible to evaluate virtual space diversity.

There is a variety of methods in the literature to evaluate quality of game levels. A few of them rely on questionnaires whereas others suggest monitoring biological changes in a player's organism. E.g. in $[6,15]$, the authors monitored biological changes in a player's organism in order to adjust the level of difficulty during gameplay. Based on the results of EEG, the system may adjust requirements of a game to maintain constant level of player's focus. Thanks to this solution, players do not feel neither bored nor frustrated.

\section{Experiment}

\subsection{Research Environment}

Research environment is constituted by a set of trail applications done with the Unreal Engine 4, each of which contains different version of the prepared game level. The environment was designed in such a way that no extra explanations or help were required. Each application consists of the following elements: start screen (defining the goal a player has to achieve and informing about a test); 


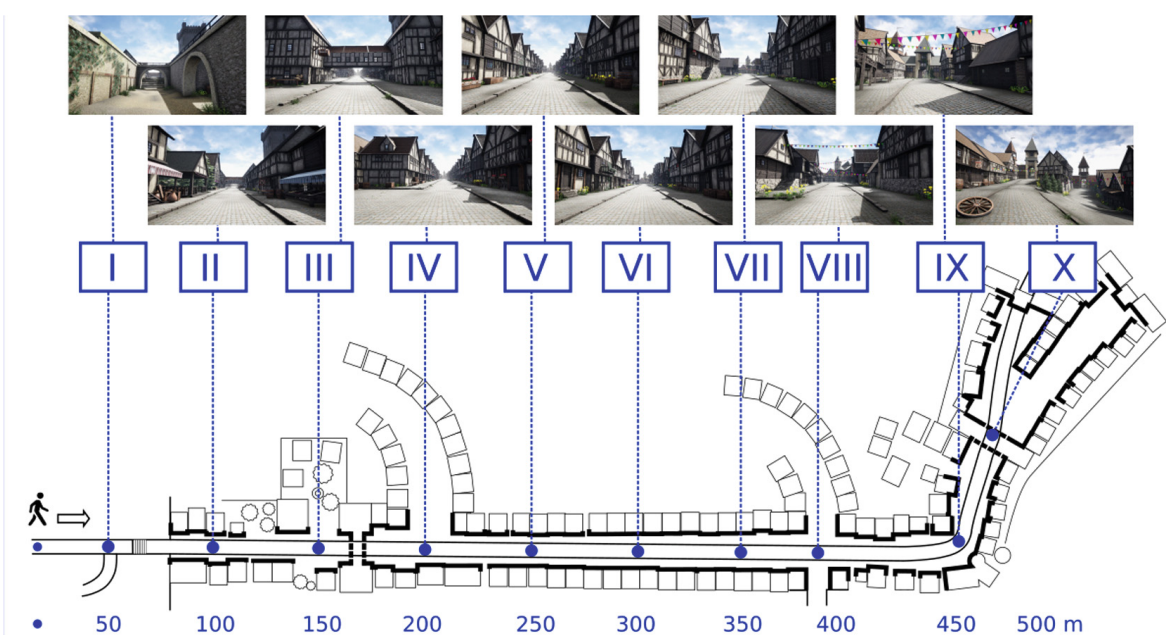

Fig. 1. Figure shows successive points where a player assess a level, as well as the visual representation of each place (for final stage of design process - main models with final materials with extra fine detailed models (called final level version).

actual game level; questionnaire to be filled with impression curve (appears every time a player has to grade a scene); and end screen.

The game level used in experiment depicts a fragment of a main road of a medieval town. The level is linear and a player, in first-person perspective, is allowed to move only along predefined path (Fig. 1). The graphics of the final level version is realistic and no stylised elements were added so as to make the virtual environment as close to the real space as possible. Thanks to this, disturbing variables influencing the level perception could be diminished. Velocity of the movement is constant (walk) and does not change in individual variants. Every 50 meters, a player stops and grades the surroundings. There are 10 such places in the entire level, hence impression curves have 10 points on time axis.

Following level variants showing successive design stages were arranged:

- Simple blockout - 3D game level sketch. Only essential elements were places on a scene, mainly buildings. Each element was constructed from one or more cuboid (A)

- Advanced blockout - detailed 3D sketch. Main level elements are presented in forms of simplified blocks (B)

- Main models without materials (C)

- Main models with monochromatic materials (D)

- Main models with final materials (E)

- Main models with final materials with extra fine detailed models (called final level version) (F)

All variants represents successive stages of level design (Fig. 2). There is a clear dependency that each next stage introduces another details to the presented 

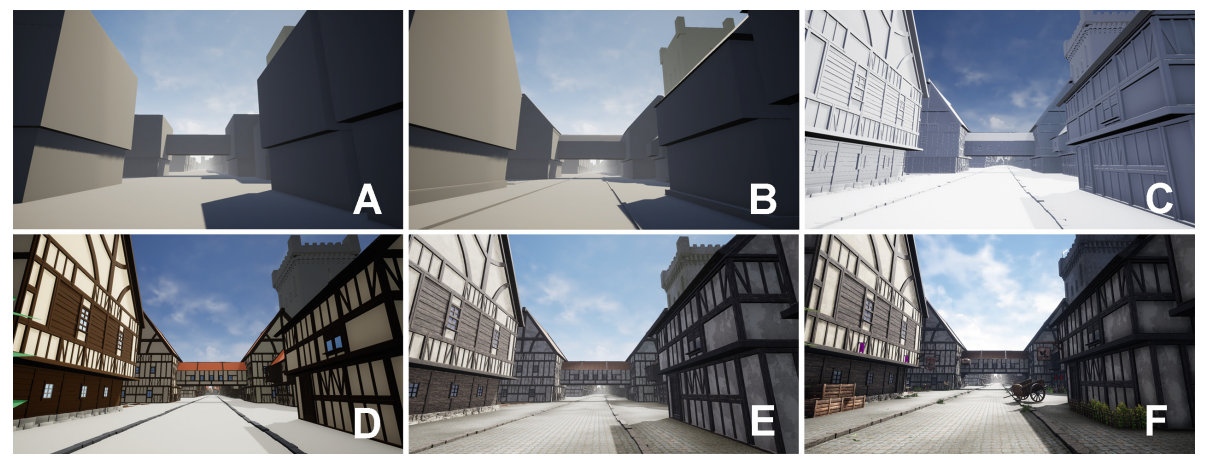

Fig. 2. The stages of computer game level design. A - simple blockout; B - advanced blockout; C - main models without materials; D- main models with monochromatic material; E - main models with final materials; F - main models with final materials with extra fine detailed models.

location. This process resembles the way a human perceives visually according to the theory of vision of David Marr [4].

\subsection{Variants of the Level with Changes of Selected Environment Elements}

In order to assess influence of other factors on the final shape of impression curve, additional trials were conducted. Following potentially influential factors, split into two groups:

1. Factors whose impact is uniform across the level - Lightening condition changes (L), Weather changes (W) (Fig. 3)

2. Factors which impact on small fragments of the level - Geometrical changes $(\mathrm{G})$, Material changes (M), Extra models and objects in the environment (O), Adding expression (X) (Fig. 4).

In order to conduct these extra tests, another variants of the level were created. Each of them let a researcher assert if a particular factor impacts on the shape of impression curve or not. Introduced changes are natural yet conspicuous. Thanks to this, it was possible to screen out a particular factor and see if the trials show it does not change the shape of impression curve. In case of level variants with lightening condition and weather changes, the general appearance of the environment was changed. The subject of those modification was the final level version.

The level variant considering changes in lightening conditions presents a medieval town by night brightened with torches. The lightening varies from uniform to the spotlight, which causes changes in distributions of fair and dark areas and increase of contrast. 

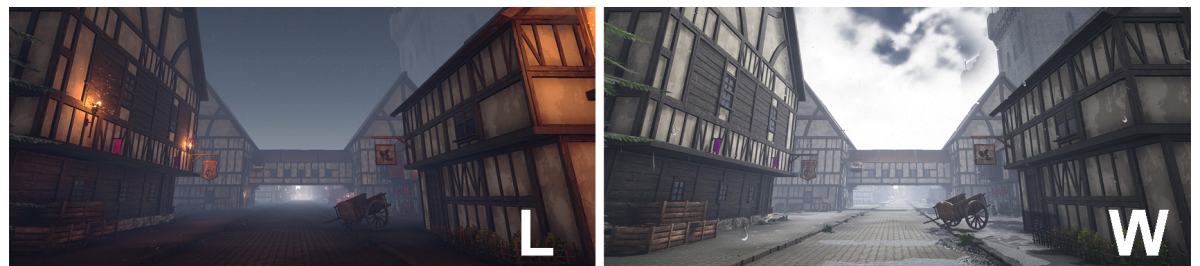

Fig. 3. Figure shows Screenshots of selected fragments of modified levels with global changes - factors whose impact is uniform across the level - Lightening condition changes (L), Weather changes (W).

The level version with weather changes depicts a town in the rain. Following extra elements were added: pools, cloudy sky, rain (done with particles), and rain drops on the screen (postprocess) (Fig. 3).

In those versions of the level which contain spot factors, the elements requiring modification were selected in advance. In each variant changes concern fifth and sixth point on the impression curve. They lie on the relatively monotonous fragment of curve where possible influence may be explicitly visible. Changes in geometry were realized as modifications of advanced blockout whereas the others - of the final version of the level.

In the case of changes in geometry, extra tall distinctive elements were added, like guard towers. Also, two houses facing each other were connected with a passage above the street.

In versions with material changes, some of the houses were modified so as to make them distinctive among other buildings and to increase the contrast. Those houses look like painted in flashy and contrasted colours.

In variant with extra models, some tiny items were placed, like a set of boxes, barrels, and a wagon, in front of a house. On the other hand, a variant with added expression was enriched by elements which could have some impact on the observer's emotions so that the level appears to be inhabited and some particular events took place there. As emotion fear was opted, since it is easy to trigger and it affects significantly. The first of the modified impression curve points contains a ruined building. Another one, blood stains leading an observer to the broken scratched doors so they appear to be attacked by an animal or a monster.

\subsection{Test Group}

Trials were conducted on 112 people. All of them were accustomed with computer games and control system (first-person perspective). Most of the people tested were students of computer science. Subjects are from 19 to 35 years old. It was assumed that one person cannot test more than one version of the level. Each variant of the level was examined by 7 to 15 people. 

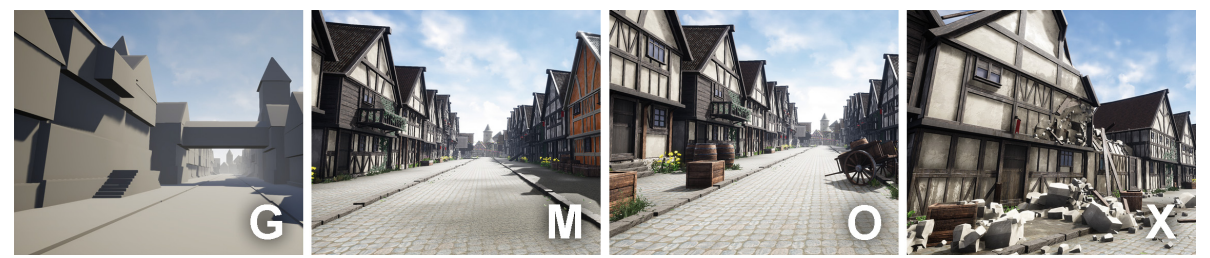

Fig. 4. Figure shows Screenshots of selected fragments of modified levels with local changes - (G) geometry, (M) material, (O) objects, (X) expression

\subsection{Experiment and Results Storing}

Each trial began with the start screen containing the description of the studies. Afterwards, participants played the levels fulfilling grading questionnaires until end screen was reached. To make trials objective and to make trials reliable, following constraints were put on experiments: no one (including a researcher) should look at the screen during a trial and a participant should not be able to see values provided by the other players.

Having done all trials, CSV file was generated. It contains the following information: an unique name of a variant, Values of impression curve for a player, time of the level accomplishment.

\subsection{Results}

For each variant of the level, the average impression curve was estimated. The values of impression curves as well as associated standard deviations are presented in Table1. (variants with successive stages of level design) and Table 3 (variants with level modifications).

The results suggest that despite the similarity of individual charts, values used by players differ. Some of them used virtually all available values from 1 to 10 whereas the others did not distinguish so much. This is the reason for relatively high values of standard deviations for individual average impression curves.

\section{Discussion}

Prior to comparing the impression curves charts, let us focus on grades given by players. Although individual shapes seem to be similar, scale used by the players differ. Some of them made use of the entire scale, unlike the others who were satisfied with values from 1 to 5 or from 5 to 10 . In order to evaluate which elements of the game level are visually appealing, local behaviour as well as local and global extrema are taken as indicators rather than particular values of impression curve.

The crucial factor which ought to be considered while assessing successive level variants is the shape of impression curve. There are several strategies to appraise similarity of the two impression curves: 


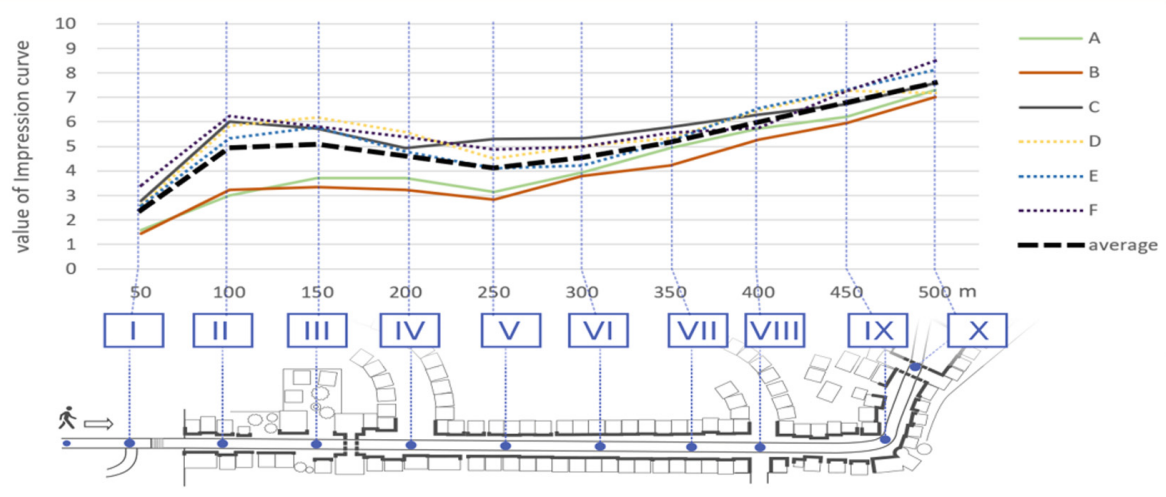

Fig. 5. The average values of impression curve for variants of levels concerning successive stages of virtual space design and the average value for all stages.

- Global minima and maxima lie in the same points or their close neighbourhood on both charts

- Local minima and maxima lie in the same points or their close neighbourhood on the two charts

- Both charts feature increasing trend in the same ranges

- Both charts feature decreasing trend in the same ranges.

\subsection{Comparison of Impression Curve Charts for Next Stages of Creating a Computer Game Level}

In Fig. 6 visual similarity of average impression curves may be seen for variants representing successive stages of level design (exact numbers with standard deviations are presented on Table 1). They are said to be similar due to the following reasons:

- Local minimum of each chart is placed in the first point of impression curve (narrow passage surrounded with wall)

- Local maximum of all charts are in second and third point (crossing a marketplace)

- Local minimum of charts are in fourth and fifth point of impression curve (beginning with the street surrounded with small houses)

- From fifth and sixth point on the impression curve, values increase up to the global maximum in the tenth (or eleventh in case of variant with monochromatic materials) point of impression curve. 

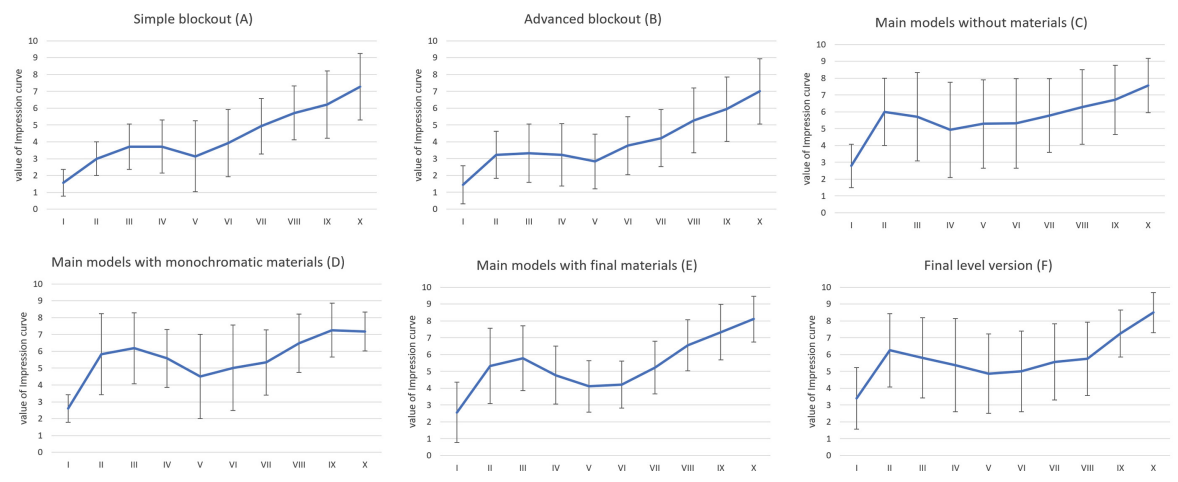

Fig. 6. Average value of impression curve - stages of the design process

Table 1. The average values of impression curve for variants of levels concerning successive stages of virtual space design and the average value for all stages. AV average value of the impression curve for each point; SD - standard deviation of the impression curve average value for each point.

\begin{tabular}{l|l|l|l|l|l|l|l|l|l|l}
\hline Curve point & I & II & III & IV & V & VI & VII & VIII & IX & X \\
\hline Simple blockout (A) \\
\hline AV & 1.57 & 3.00 & 3.71 & 3.71 & 3.14 & 3.93 & 4.93 & 5.71 & 6.21 & 7.29 \\
\hline SD & 0.79 & 1.00 & 1.35 & 1.58 & 2.12 & 2.01 & 1.64 & 1.60 & 2.00 & 1.98 \\
\hline Advanced blockout (B) \\
\hline AV & 1.44 & 3.22 & 3.33 & 3.22 & 2.83 & 3.78 & 4.22 & 5.28 & 5.94 & 7.00 \\
\hline SD & 1.13 & 1.39 & 1.73 & 1.86 & 1.62 & 1.72 & 1.70 & 1.92 & 1.91 & 1.94 \\
\hline Main model without material (C) \\
\hline AV & 2.79 & 6.00 & 5.71 & 4.93 & 5.29 & 5.31 & 5.79 & 6.29 & 6.71 & 7.57 \\
\hline SD & 1.29 & 2.00 & 2.63 & 2.83 & 2.63 & 2.66 & 2.20 & 2.21 & 2.06 & 1.62 \\
\hline Main model with momochromatic material (D) \\
\hline AV & 2.61 & 5.84 & 6.18 & 5.58 & 4.50 & 5.02 & 5.34 & 6.48 & 7.26 & 7.18 \\
\hline SD & 0.82 & 2.41 & 2.11 & 1.72 & 2.51 & 2.54 & 1.94 & 1.74 & 1.61 & 1.16 \\
\hline Main model with final material (E) \\
\hline AV & 2.57 & 5.33 & 5.78 & 4.78 & 4.11 & 4.22 & 5.22 & 6.56 & 7.33 & 8.11 \\
\hline SD & 1.80 & 2.24 & 1.92 & 1.72 & 1.54 & 1.39 & 1.56 & 1.51 & 1.66 & 1.36 \\
\hline Main model with final material with extra fined detailed model - final level version (F) \\
\hline AV & 3.40 & 6.25 & 5.81 & 5.38 & 4.88 & 5.00 & 5.56 & 5.75 & 7.25 & 8.50 \\
\hline SD & 1.83 & 2.19 & 2.39 & 2.77 & 2.36 & 2.39 & 2.26 & 2.19 & 1.39 & 1.20 \\
\hline
\end{tabular}




\subsection{Comparison of the Highest, Lowest and Average Values of the Impression Curves for Next Stages of Creating a Computer Game Level}

Table 2 contains the lowest, the highest and the average values of impression curve for variants of levels concerning successive stages of virtual space design:

- For "Simple blockout" (A) and "Advanced blockout" (B) those values are the lowest ones

- For variant "Main models without materials" $(\mathrm{C})$, "Main models with monochromatic materials"(D) and "Main models with final materials"(E) those values are higher than in case of "Simple blockout" (A) and lower than for the "final level version" (E).

- Value of impression curve are highest for "Final level version - Main models with final materials with extra fine detailed models" $(\mathrm{F})$.

The above data indicates that the more advanced stage of level design, the higher values of impression curve occur. Both the average and extreme values grow.

Table 2. The highest, lowest and average values of the impression curve for individual level variants, showing the next stages of work on the virtual environment.

\begin{tabular}{l|l|l|l}
\hline \multirow{2}{*}{ Stage of design process } & \multicolumn{3}{l}{ Value of impression curve } \\
\cline { 2 - 4 } & Lowest value & $\begin{array}{l}\text { Highest } \\
\text { value }\end{array}$ & $\begin{array}{l}\text { Average } \\
\text { value }\end{array}$ \\
\hline Simple blockout (A) & 1.57 & 7.29 & 4.32 \\
\hline Advanced blockout (B) & 1.44 & 7.00 & 4.03 \\
\hline Main model without material (C) & 2.79 & 7.57 & 5.64 \\
\hline Main model with momochromatic material (D) & 2.61 & 7.26 & 5.60 \\
\hline Main model with final material (E) & 2.57 & 8.11 & 5.40 \\
\hline Final level version (F) & 3.40 & 8.50 & 5.78 \\
\hline
\end{tabular}

\subsection{Comparison of Impression Curve Charts for Modified Variants of the Computer Game Level}

Having confirmed that impression curves for successive stages of level design are alike, curves for modified versions of the level might be compared. This should provide the information which modifications have the effect on impression curve.

In Fig. 7 and Fig. 8 visual similarity of average impression curves for modified levels may be juxtaposed with the curve of any stage of level design process (exact numbers with standard deviations are presented on Table 3 ). It may be noted that:

- Changes of weather, lightening conditions and materials do not impact on the shape of impression curve 

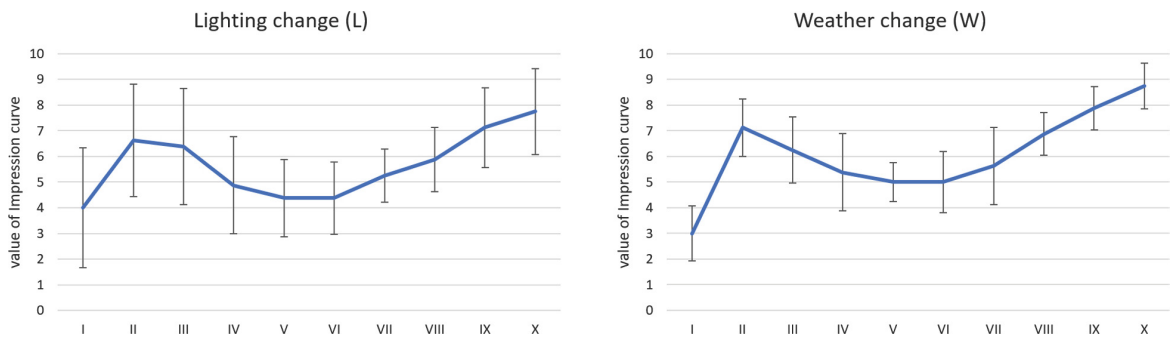

Fig. 7. Average value of impression curve - variants with global changes - (W) weather, (L) Lighting
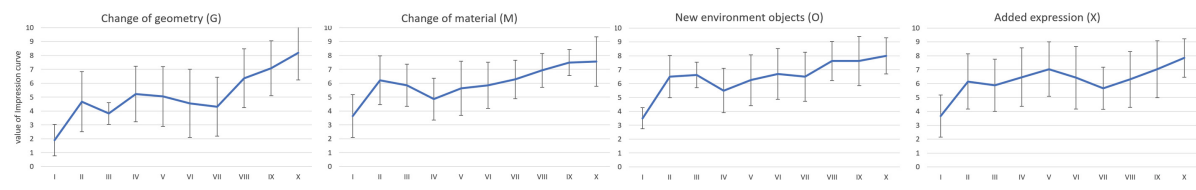

Fig. 8. Average value of impression curve - variants with level modifications - local changes - $(\mathrm{G})$ geometry, $(\mathrm{M})$ material, $(\mathrm{O})$ objects, $(\mathrm{X})$ expression

Table 3. The average values of impression curve for variants of levels concerning successive stages of virtual space design and the average value for all stages. AV average value of the impression curve for each point; SD - standard deviation of the impression curve average value for each point.

\begin{tabular}{l|l|l|l|l|l|l|l|l|l|l}
\hline Curve point & I & II & III & IV & V & VI & VII & VIII & IX & X \\
\hline Weather change (rain) \\
\hline AV & 3.00 & 7.13 & 6.25 & 5.38 & 5.00 & 5.00 & 5.63 & 6.88 & 7.88 & 8.75 \\
\hline SD & 1.07 & 1.13 & 1.28 & 1.51 & 0.76 & 1.20 & 1.51 & 0.83 & 0.83 & 0.89 \\
\hline Change of geometry - advanced blockout \\
\hline AV & 1.91 & 4.68 & 3.82 & 5.23 & 5.05 & 4.55 & 4.32 & 6.36 & 7.09 & 8.18 \\
\hline SD & 1.14 & 2.17 & 0.78 & 1.99 & 2.15 & 2.45 & 2.12 & 2.11 & 1.97 & 1.94 \\
\hline Adding expression \\
\hline AV & 3.65 & 6.15 & 5.88 & 6.46 & 7.05 & 6.42 & 5.65 & 6.31 & 7.04 & 7.85 \\
\hline SD & 1.52 & 1.99 & 1.87 & 2.11 & 1.96 & 2.25 & 1.52 & 2.02 & 2.05 & 1.39 \\
\hline Change of materials & 3.64 & 6.21 & 5.86 & 4.86 & 5.64 & 5.86 & 6.29 & 6.93 & 7.50 & 7.57 \\
\hline AV & 1.55 & 1.76 & 1.51 & 1.51 & 1.95 & 1.66 & 1.38 & 1.21 & 0.94 & 1.79 \\
\hline SD & 3.50 & 6.50 & 6.63 & 5.50 & 6.25 & 6.69 & 6.50 & 7.63 & 7.63 & 8.00 \\
\hline New environment objects & & & \\
\hline AV & 0.76 & 1.51 & 0.92 & 1.60 & 1.83 & 1.83 & 1.77 & 1.41 & 1.77 & 1.31 \\
\hline SD & 4.00 & 6.63 & 6.38 & 4.88 & 4.38 & 4.38 & 5.25 & 5.88 & 7.13 & 7.75 \\
\hline Lighting change (night) & & & & \\
\hline AV & 2.33 & 2.20 & 2.26 & 1.89 & 1.51 & 1.41 & 1.04 & 1.25 & 1.55 & 1.67 \\
\hline SD
\end{tabular}


- For variants enriched by expression elements or tiny surrounding items, the curve grew and reached a local maximum in the modified locations (fifth and sixth point on impression curve)

- Changes in geometry dramatically influence the impression curve. The values of curve decrease for points from fourth to seventh on the impression curve.

\section{Summary and Conclusions}

The goal of this paper was to examine, by means of impression curve, how visual perception varies throughout successive stages of level design process as well as to identify factors which influence on scene perception by a player. To conduct studies, several variants of the same level were prepared. Each version was tested by players. All presented charts contain average impression curves which were compared to one another (Fig. 5).

Based on conducted experiments, following conclusions might be drawn:

- The method of impression curve could be a useful tool to assess virtual worlds, especially in case of game level design. It is supposed to support the design of virtual worlds being visually appealing and diversified, where the gameplay and appearance complement each other

- Charts of average impression curves for successive stages of level design are alike. This means that the virtual environment may be tested with impression curve from the very beginning

- The more advanced the design phase, the higher average impression curve values are

- Disturbances of buildings blocks (geometry changes, extra tiny items, added expression) have impact on the shape of impression curve

- Neither lightening condition changes, nor weather or material changes influence impression curve

There are possible following directions of further research: investigation of dependency between player's reaction and forming of the impression curve (eyetracking [20], EEG [21]), examination if graphical style or perspective (used camera type) have any impact on the impression curve or check if the strategy of impression curve can be used for $2 \mathrm{D}$.

\section{References}

1. Senetra, A., Szczepańska, A., Bajerowski, T., Wycena krajobrazu. In: Rynkowe aspekty oceny i waloryzacji krajobrazu, Educaterra, Olsztyn, PL (2000)

2. Cox, D.J.: Interior design and environment art: mastering space. In: Mastering Place on Game Developers Conference 2015 (2015). Accessed 21 May 2019

3. Cox, D.J.: What Modern Interior Design Teaches Us About Environment Art on Game Developers Converence 2014 (2014). Accessed 21 May 2019

4. Marr, D.: Vision. The MIT Press, Cambridge (2010)

5. Jenkins, H.: Game design as narrative architecture. Computer 44, 118-30 (2004) 
6. Mikami, K., Kondo, K.: Adaptable game experience based on player's performance and EEG. In: 2017 Nicograph International (NicoInt), Kyoto, JP, pp. 1-8 (2017). https://doi.org/10.1109/NICOInt.2017.11

7. Solecka, I.: Polish experience in landscape identyfication and valorisation. Inżynieria Ekologiczna 2016(50), 223-231 (2016)

8. Wejchert, K.: Elementy kompozycji urbanistycznej. Arkady, Warszawa (1984)

9. Norman, K.: GEQ (Game Engagement/Experience Questionnaire): a review of two papers. Interact. Comput. 25(4), 278-283 (2013)

10. Zając, M., Bałaga, K., Janicki, G.: Waloryzacja krajobrazu podmiejskiej wsi (okolice Lublina) dla potrzeb gospodarki przestrzennej. Problemy Ekologii Krajobrazu 2014(37), 77-86 (2014)

11. Ølsted, P.T., Ma, B., Risi, S.: Interactive evolution of levels for a competitive multiplayer FPS. In: IEEE Congress on Evolutionary Computation (CEC), Sendai, JP, pp. 1527-1534 (2015). https://doi.org/10.1109/CEC.2015.7257069

12. Szrajber, R.: Architecture in virtual worlds as a field of research. In: Fross, Klaudiusz (ed.) book: Badania Interdyscyplinarne w Architekturze 2, vol. 1, pp. 55-66. Wydział Architektury Politechniki Śląskiej, Gliwice (2017)

13. Szrajber, R.: Impression Curve and the Gameplay Curve as an Attempt to Record the Player's Experience during International Conference for Young Researchers Computer Game Cultures 2: Game as an Experience, 26-28 June. Lodz, PL (2014)

14. Szrajber, R.: Architecture in Video Games - Seeing or Experiencing during International Conference for Young Researchers - Computer Game Cultures 4: Criticism and Methodology, 30 June, Lodz, PL (2017)

15. Berta, R., Bellotti, F., De Gloria, A., Pranantha, D., Schatten, C.: Electroencephalogram and physiological signal analysis for assessing flow in games. IEEE Trans. Comput. Intell. AI Games 5(2), 164-175 (2013). https://doi.org/10.1109/ TCIAIG.2013.2260340

16. Almeida, S., Veloso, A., Roque, L., Mealha, O., Moura, A.: A video game level analysis model proposal. In: 16th International Conference on Information Visualisation, pp. 474-479 (2012). https://doi.org/10.1109/IV.2012.82

17. Freytag, S.-C., Wienrich, C.: Evaluation of a virtual gaming environment designed to access emotional reactions while playing. In: 9th International Conference on Virtual Worlds and Games for Serious Applications (VS-Games), Athens, 2017, pp. 145-148 (2017). https://doi.org/10.1109/VS-GAMES.2017.8056585

18. Litwin, U., Bacior, S., Piech, I.: Metodyka waloryzacji i oceny krajobrazu. Geodezija, kratografija i aerofotoznimanie 70, 14-25 (2009)

19. IJsselsteijn, W.A., de Kort, Y.A.W., Poels, K., Jurgelionis, A., Bellotti, F.: Characterising and measuring user experiences in digital games. In: Bernhaupt, R., Tscheligi, M. (eds.) Proceedings of the International Conference on Advances in Computer Entertainment Technology (ACE 2007), 13-15 June 2007, pp. 1-4. Salzburg, Austria (2007)

20. Rynkiewicz, F., Daszuta, M., Napieralski, P.: Pupil detection methods for eye tracking. J. Appl. Comput. Sci. 26(2) (2018). pp. 201-211. Technical University Press, Łódź, Poland, ISSN 1507-0360

21. Opałka, S., Stasiak, B., Szajerman, D., Wojciechowski, A.: Multi channel convolutional neural networks architecture feeding for effective EEG mental tasks classification. Sensors 18(10), 3451 (2018). https://doi.org/10.3390/s18103451 